\title{
Keratinization Inhibition
}

National Cancer Institute

\section{Source}

National Cancer Institute. Keratinization Inhibition. NCI Thesaurus. Code C40824.

Keratinization Inhibition involves interference with, or restraint of, activities involved in proliferation and maturation of tightly bound keratinocytes transiting passively from the basal to the corneal layer of the skin. 